\title{
Nucleophilic ring opening of 1,2-epoxides in aqueous medium
}

\author{
David Amantini, Francesco Fringuelli*, Oriana Piermatti, Simone Tortoioli, and Luigi \\ Vaccaro
}

Dipartimento di Chimica, Università di Perugia via Elce di Sotto, 806100 Perugia, Italy

E-mail: frifra@unipg.it

\begin{abstract}
Dedicated to Professor Domenico Spinelli on the occasion of his $70^{\text {th }}$ birthday
(received 10 Oct 02; accepted 28 Feb 03; published on the web 08 Mar 03)
\end{abstract}

\begin{abstract}
Nucleophilic ring opening of 1,2-epoxides in aqueous medium in the presence and absence of metal salts is reviewed. Azidolysis, hydrolysis, iodolysis and thiolysis are the reactions mainly investigated. The $\mathrm{pH}$ of the reaction medium controls the reactivity and regioselectivity of the process. By working at suitable $\mathrm{pH}$ values, even salts such as $\mathrm{AlCl}_{3}, \mathrm{SnCl}_{4}$ and $\mathrm{TiCl}_{4}$ are active catalysts.
\end{abstract}

Keywords: 1,2-Epoxides, azidolysis, hydrolysis, thiolysis, lewis-acid catalysts

\section{Introduction}

Sustainable development requires redesigning many organic chemical processes, most of which are often based on technology developed in the first half of the 20th century, and inventing new reactions that use and produce safer chemicals under more environmentally benign conditions. ${ }^{1}$ Considerable interest has developed in the use of water in organic synthesis either at "normal" temperature $\left(3-150{ }^{\circ} \mathrm{C}, 1-5 \mathrm{~atm}\right)$, or elevated temperature $\left(250-350{ }^{\circ} \mathrm{C}, 40-170 \mathrm{~atm}\right)$ or in supercritical conditions $\left(400{ }^{\circ} \mathrm{C}, 250-500 \mathrm{~atm}\right) .{ }^{2}$ At elevated temperature and pressure the spatial structures of water changes significantly and consequently the physiochemical properties such as dielectric constant, density, solubility parameter and dissociation constant change dramatically. ${ }^{3}$ Under these severe conditions water can act either as a reagent or as an acid or basic catalyst and many non-polar organic substrates and gases are soluble in the aqueous phase facilitating or making organic reactions possible that were previously thought to occur only in the presence of a strong acid or base or in organic solvent.

Working at elevated temperature and pressure requires high investment costs because the reactions must be carried out in an autoclave (superheated water) or in complex apparatus 
(supercritical water) and because special materials are required to overcome problems of corrosion.

The water used in aqueous organic reactions carried out under "normal" conditions of temperature and pressure, acts mainly as a reaction medium; a special, active reaction medium. Liquid water has physiochemical properties that are indeed very different from those of organic solvents: its molecular volume is small, the cohesive pressure is the highest and the internal pressure is the lowest, the surface tension is very large and the heat capacity, heat fusion and heat vaporization are high. ${ }^{4}$ These properties are the consequence of intermolecular forces between closed-shell molecules.

The aqueous medium offers notable advantages with respect to the organic solvent: (i) it is abundant, cheap, non-toxic, non-inflammable, (ii) because of its high heat capacity, it is a heat sink, (iii) the protection-deprotection of functional groups such as $-\mathrm{OH},-\mathrm{NH}_{2}$ and $-\mathrm{COOH}$ may be unnecessary, (iv) water-soluble compounds can be used directly without derivatization, (v) the reaction products can sometimes be isolated simply by decantation or filtration, (vi) salts, surfactants and cyclodextrins can be used, and (vii) the $\mathrm{pH}$ of the reaction medium can be controlled which strongly affects the rate and selectivity of the reaction and allows the reaction to be carried out one-pot by domino or consecutive procedures. ${ }^{5}$

Reactions in water often proceed faster than in organic solvents even if one or more reagents and products seem to be insoluble. The use of a co-solvent, to favor the solubility of reagents, does not always favor the reactivity and selectivity of the process.

To date pericyclic, condensation, oxidation and reduction reactions are routinely carried out in aqueous medium. ${ }^{6}$ The use of Lewis-acids such as lanthanide triflates $\mathrm{Bi}(\mathrm{OTf})_{3}, \operatorname{Sc}(\mathrm{OTf})_{3}$, $\mathrm{Y}(\mathrm{OTf})_{3}, \mathrm{InCl}_{3}, \mathrm{InBr}_{3}, \mathrm{In}(\mathrm{OTf})_{3}$ has revolutionized the organometallic chemistry. ${ }^{6 \mathrm{~b}}$ Recently we have shown that Lewis acid catalysis in water is strongly dependent on the $\mathrm{pH}$ of the aqueous medium and, by maintaining the $\mathrm{pH}$ at a suitable level, it is possible to use Lewis acids such as $\mathrm{AlCl}_{3}, \mathrm{TiCl}_{4}$ and $\mathrm{SnCl}_{4}$, for which anhydrous conditions are usually recommended, in water. ${ }^{7}$

To date the underlying reasons of the role of the water as reaction medium are still not clear. The inner structure of the liquid water is complex and none of the proposed models completely describes its physiochemical properties. Hydrophobic and hydrogen bonding interactions and polarity are the main factors that influence the reactivity and selectivity of the process. ${ }^{4,8}$

The 1,2-epoxide functionality is largely present in nature, is biologically important and is a powerful building block in organic synthesis. ${ }^{9}$ Recently Sharpless, ${ }^{10}$ following the chemical lead of mother nature, proposed to term "click chemistry" the synthetic approach that generates substances "by joining small units together with heteroatom links (C-X-C)" and defined the criteria that a process must meet to be useful in this context. A "click reaction" that uses this strategy is the nucleophilic ring-opening of 1,2-epoxides.Moreover Sharpless notes that "many of the reactions that meet the click chemistry standard often proceed better (faster and more selectivity) in water than in organic solvents. Nucleophilic additions to epoxide electrophiles are favored by solvents best able to respond continuously to the demanding range of hydrogen- 
bonding situations that arise during these processes. In this respect water is unique as reaction medium."

An overview of nucleophilic ring opening reactions in aqueous media of the 1,2-epoxide functionality present in various compounds, is presented.

\section{Reactions in the absence of metal salts}

Azidolysis of 1,2-epoxides is a widely investigated organic reaction because 1,2-azidoalcohols are precursors of vicinal aminoalcohols and are building blocks for carbohydrates and nucleosides. ${ }^{11}$

The classical protocol uses $\mathrm{NaN}_{3}(5 \mathrm{~mol} / \mathrm{eq})$ as reagent in the presence of $\mathrm{NH}_{4} \mathrm{Cl}(2.3 \mathrm{~mol} / \mathrm{eq})$ as coordinating salt in alcohol-water at $70-80{ }^{\circ} \mathrm{C}$. Some examples are illustrated in Table $1^{12}$ and Scheme $1 .^{13,14}$

Table1. Azidolysis of 1,2-epoxides by sodium azide in aqueous methanol

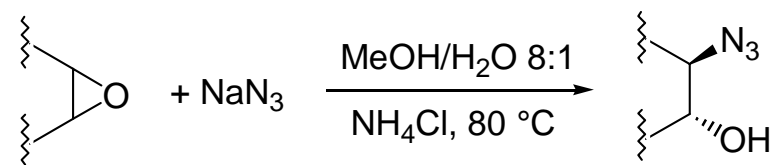

\begin{tabular}{|c|c|c|c|c|}
\hline Entry & Epoxide & $\mathrm{t}(\mathrm{h})$ & $C-\beta / C-\alpha$ & Yield $(\%)$ \\
\hline 1 & & 36 & & 92 \\
\hline 2 & & 48 & $73 / 27$ & 94 \\
\hline 3 & $\beta$ & 18 & $99 / 1$ & 89 \\
\hline 4 & & 16 & $17 / 83$ & 85 \\
\hline 5 & & 24 & $95 / 5$ & 94 \\
\hline 6 & & 20 & $21 / 79$ & 94 \\
\hline 7 & $\underbrace{}_{\beta} \underbrace{}_{\alpha}{ }^{\mathrm{CH}_{2} \mathrm{OP}}$ & 12 & $99 / 1$ & 95 \\
\hline
\end{tabular}


Under these conditions the reaction is completely anti-stereoselective and generally requires a long reaction time. The attack of nucleophile on substituted oxirane ring occurs mainly on the least substituted carbon except when the substituent is an aryl group.

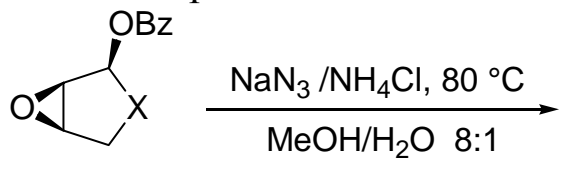

1<smiles>[R16]C1C[C@H](N)C(O)C1[18OH]</smiles>

2

\begin{tabular}{lllc}
$\mathbf{1}$ & $\mathrm{t}(\mathrm{h})$ & $\mathbf{2 / 3}$ & Yield (\%) \\
\hline $\mathrm{X}=\mathrm{CH}_{2}$ & 18 & $93 / 7$ & 95 \\
$\mathrm{X}=\mathrm{O}$ & 60 & $84 / 16$ & 96
\end{tabular}

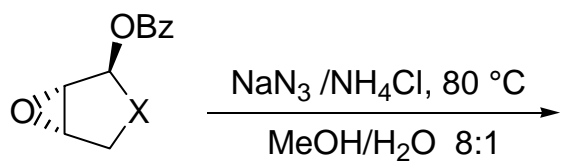

4

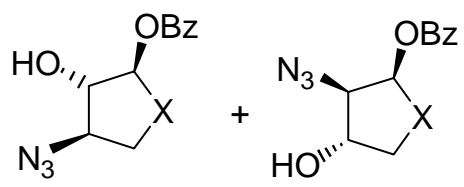

5

6

\begin{tabular}{lllc}
$\mathbf{4}$ & $\mathrm{t}(\mathrm{h})$ & $\mathbf{5 / 6}$ & Yield (\%) \\
\hline $\mathrm{X}=\mathrm{CH}_{2}$ & 18 & $99 / 1$ & 91 \\
$\mathrm{X}=\mathrm{O}$ & 60 & $99 / 1$ & 94
\end{tabular}<smiles>CC1(C)OC2C=C[C@H]3O[C@H]3C2O1</smiles><smiles>CC1(C)OC2C=C[C@H](N)[C@H](O)C2OC1(C)C[SbH2]O</smiles>

$87 \%$<smiles></smiles>

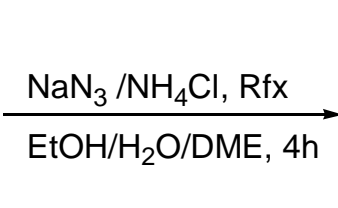<smiles>CC1(C)OC2C(Cl)=C[C@@H](N)[C@H](O)C2O1</smiles>
$72 \%$

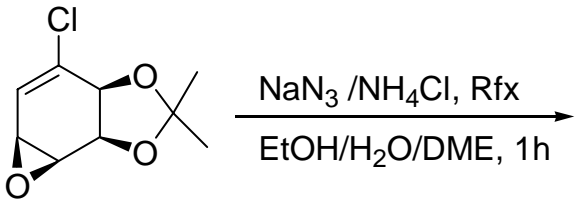<smiles>CC1(C)OC2C(Cl)=C[C@@H](N)C(O)C2O1</smiles>

$87 \%$

Scheme 1. Azidolysis of 1,2-epoxides by sodium azide in aqueous organic media. 


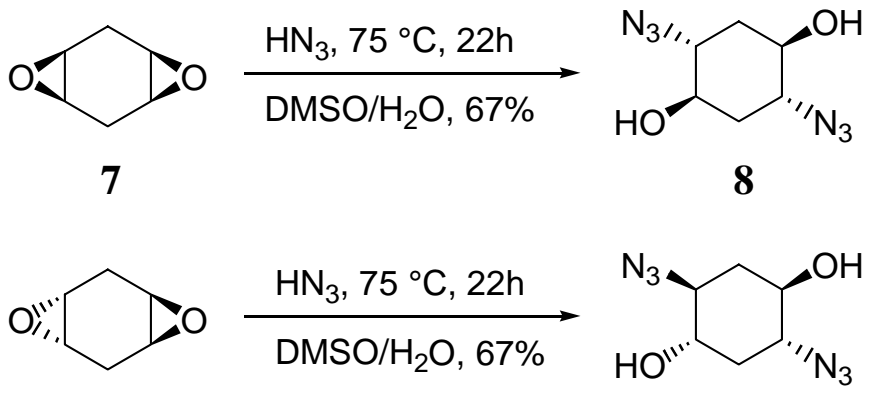

9

10

Scheme 2. Azidolysis of diepoxycyclohexane.

In this case the nucleophilic attack generally occurs mainly on the benzylic carbon (Table 1, entries 4 and 6). In the absence of a specific substituent on the $\alpha$-and $\beta$-carbons of the oxirane ring, the nucleophile preferentially attacks the carbon which is less influenced by unfavorable effects of electron-withdrawing functionalities present in the molecule (Scheme1).

Table 2. Azidolysis in water of 1,2-epoxides by sodium azide at $30{ }^{\circ} \mathrm{C}$

\begin{tabular}{|c|c|c|c|c|c|}
\hline Entry & Epoxide & $\mathrm{pH}$ & $\mathrm{t}(\mathrm{h})$ & $C-\beta / C-\alpha$ & Yield $^{\mathrm{a}}(\%)$ \\
\hline \multirow{2}{*}{1} & & 9.5 & 12 & & 90 \\
\hline & & 4.2 & 0.5 & & 90 \\
\hline \multirow{2}{*}{2} & & 9.5 & 12 & $65 / 35$ & 50 \\
\hline & & 4.2 & 0.5 & $21 / 79$ & 65 \\
\hline \multirow{2}{*}{3} & & 9.5 & 60 & $65 / 35$ & $55^{\mathrm{c}}$ \\
\hline & & 4.2 & 48 & $14 / 86$ & $70^{\mathrm{b}}$ \\
\hline \multirow[b]{2}{*}{4} & & 9.5 & 20 & $97 / 3$ & 77 \\
\hline & & 4.2 & 1.5 & $30 / 70$ & $58^{\mathrm{b}}$ \\
\hline \multirow{2}{*}{5} & & 9.5 & 24 & $96 / 4$ & $88^{\mathrm{b}}$ \\
\hline & & 4.2 & 4 & $70 / 30$ & \\
\hline \multirow{2}{*}{6} & & 9.5 & 28 & $98 / 2$ & $90^{\mathrm{b}}$ \\
\hline & & 4.2 & 3 & $15 / 85$ & 70 \\
\hline \multirow{2}{*}{7} & & 9.5 & 13 & $3 / 97$ & 90 \\
\hline & & 4.2 & 0.3 & $3 / 97$ & 92 \\
\hline
\end{tabular}

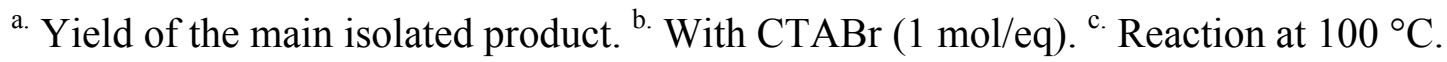


Azidolysis of cis- and trans- 1,4-diepoxycyclohexanes 7 and 9 (Scheme 2) with hydrazoic acid, generated in situ from $\mathrm{NaN}_{3}$ and $p$-toluenesulfonic acid, carried out in 1:1 DMSO/ $\mathrm{H}_{2} \mathrm{O}$ mixture at $70^{\circ} \mathrm{C}$, gave the azidoalcohols 8 and 10, respectively, as sole products which were converted to corresponding aminocyclitols with good yields by catalytic reduction. ${ }^{15}$

The reason for using an aqueous-organic medium for the azidolysis of 1,2-epoxides is to carry out the reaction under homogeneous conditions solubilizing both the sodium azide (water) and the epoxide (organic solvent). Recently we have shown ${ }^{5 c}$ that the azidolysis of 1,2-epoxides can be suitably performed in water alone under heterogeneous conditions. The nucleophilic addition was totally anti-diastereoselective and the reactivity and regioselectivity of the process and the competition of the azido ion with the water or with the hydroxide ion were controlled by working at suitable $\mathrm{pH}$ values. Some results are reported in Table 2. The conversion of 1,2epoxide into azidoalcohol was quantitative. With highly hydrophobic epoxides, the azidolysis was accelerated by carrying out the reaction in the presence of cetyltrimethylammonium bromide (CTABr).

At $\mathrm{pH} 9.5$ the attack of azide ion preferentially occurred, as expected, on the less substituted $\beta$-carbon of all epoxides with the exception of styrene oxide (Table 2 entry 7) in which the nucleophile predominately attacked the more substituted benzylic $\alpha$-carbon. Under acidic conditions ( $\mathrm{pH} 4.2$ ), the reaction was strongly accelerated and a reversed regioselectivity, or an increment of $\alpha$-attack, was observed for all epoxides except styrene oxide.

Table 3. $\alpha / \beta$ Cyclization products of 2'-hydroxychalcone epoxides

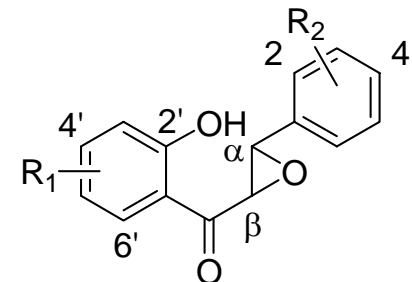

11

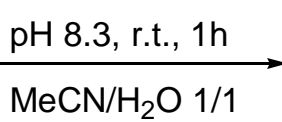

$\mathrm{MeCN} / \mathrm{H}_{2} \mathrm{O}$ 1/1

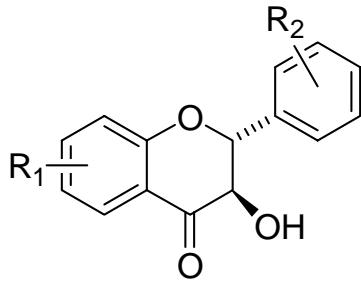

12

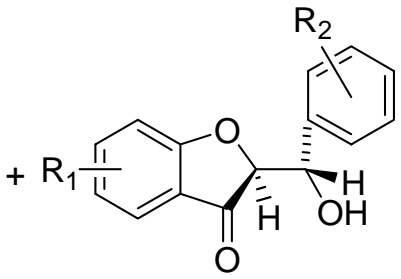

13

\begin{tabular}{ccc}
\hline $\mathrm{R}_{1}$ & $\mathrm{R}_{2}$ & $12 / 13(\alpha / \beta)$ \\
\hline $\mathrm{H}$ & $\mathrm{H}$ & $100: 0$ \\
6'-OMe & $\mathrm{H}$ & $14: 86$ \\
6'-OiPr & $\mathrm{H}$ & $16: 84$ \\
4',6'-(OMe $)_{2}$ & $\mathrm{H}$ & $15: 85$ \\
$\mathrm{H}$ & $4-\mathrm{Cl}$ & $10: 90$ \\
$\mathrm{H}$ & $2-\mathrm{CF}_{3}$ & $0: 100$ \\
\hline
\end{tabular}


The regioselectivity under acidic conditions is explained by considering that the attack of the azido ion on the more substituted $\alpha$-carbon arises from the prior protonation of the epoxide, which produces a considerably more positive charge on the tertiary $\alpha$-carbon than on the secondary or primary one. Coupling these results with the epoxidation of alkenes and the reduction of azides in water, 16,17 1,2-azidoalcohols from alkenes and aminoalcohols from epoxides can be prepared by a one-pot procedure in water alone as reaction medium.
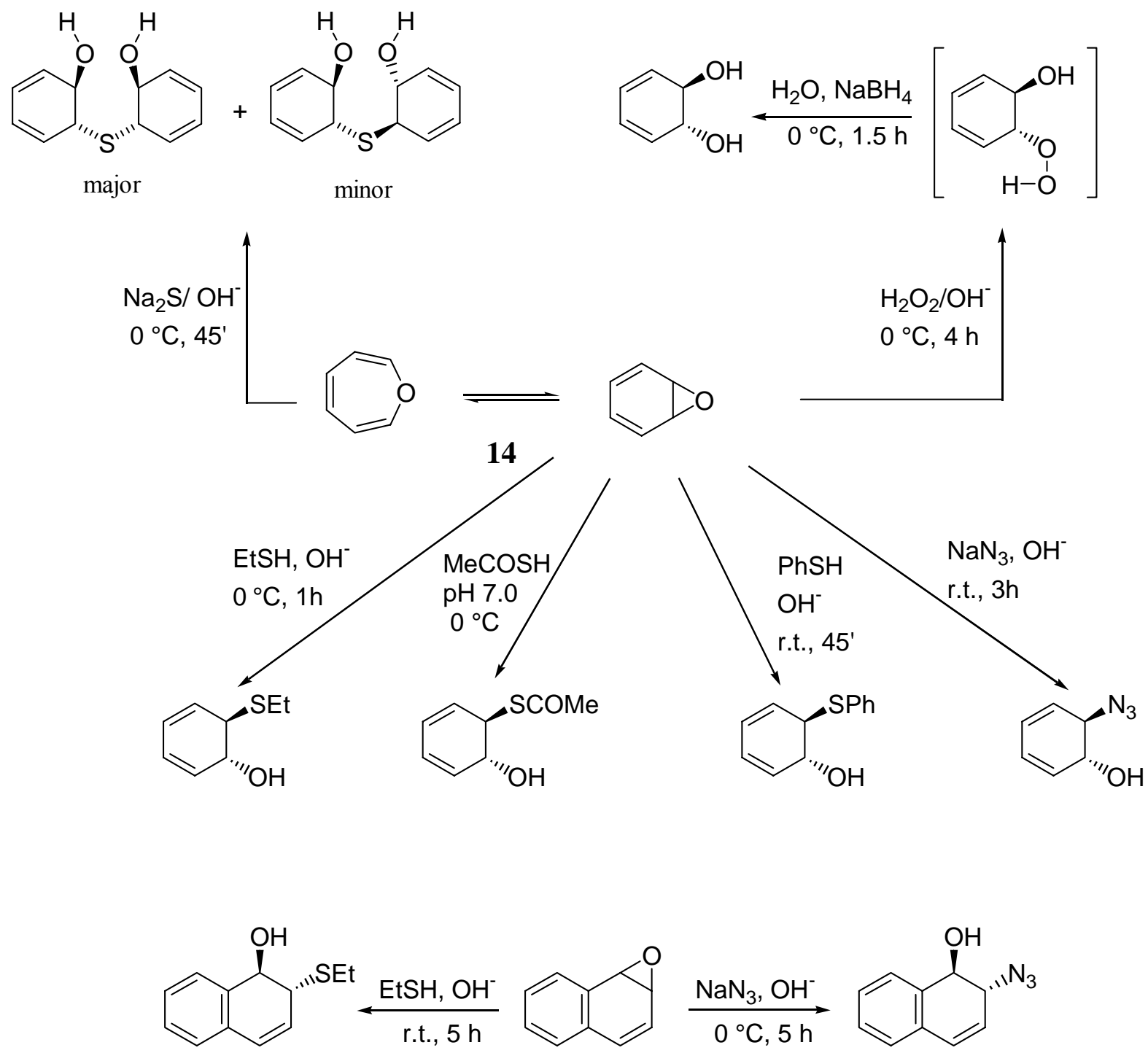

15

Scheme 3. Reactions of benzene oxide-oxepin and naphthalene 1,2-oxide with various nucleophiles.

Nucleophilic attack on a phenyl-substituted epoxide is not always controlled by the benzylic nature of the $\alpha$-carbon atom. The intramolecular cyclization of 2'-hydroxychalcones $\mathbf{1 1}$ is an 
example. ${ }^{18}$ Under neutral or weakly basic conditions in $1: 1 \mathrm{MeCN} / \mathrm{H}_{2} \mathrm{O}$ mixture, the unsubstituted chalcone $11\left(R_{1}=R_{2}=H\right)$ gave the expected 3-hydroxyflavone $12\left(R_{1}=R_{2}=H\right)$, while the erythro-aurone-hydrates $\mathbf{1 3}$ were the main reaction products when alkoxy substiutents were present in the benzene rings in conjugative position (Table 3). The prevalence of $\beta$ cyclization was explained on the basis of stereoelectronic factors.

Another example is the azidolysis of styrene oxide carried out in the presence of $\beta$ cyclodextrin $(\beta-\mathrm{CD})$ in water at room temperature. ${ }^{19}$ Thus using $\mathrm{LiN}_{3}$ and $2 \mathrm{~mol} / \mathrm{eq}$ of $\beta-\mathrm{CD}$, the reaction conversion after $17 \mathrm{~h}$ was $72 \%$, the $\alpha / \beta$ ratio 50:50 and the ee of the adduct coming from the $\beta$-attack was $78 \%$ in favor of the $(\mathrm{R})$ enantiomer.

Due to the importance of substituted 1,3-cyclohexadienes in nature and the role of arene oxide-oxepin system in their formation, the ring opening of benzene oxide-oxepin 14 and naphthalene-1,2-oxide 15 were investigated. ${ }^{20}$ The oxide 14 reacted with various nucleophiles in water under neutral-basic conditions to give 5,6-trans-substituted-1,3-cyclohexadienes (Scheme 3).<smiles></smiles>

16<smiles>O[C@H]1C2=C(CCCC2)[C@@H](O)[C@@H](O)[C@@H]1O</smiles>

18a (cis)

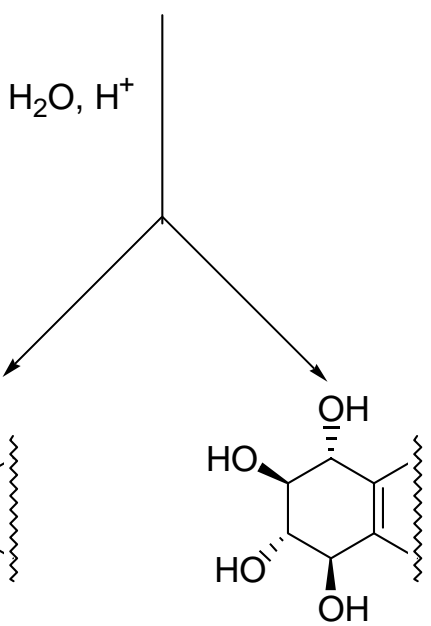

$18 \mathbf{b}(\operatorname{trans})$<smiles></smiles>

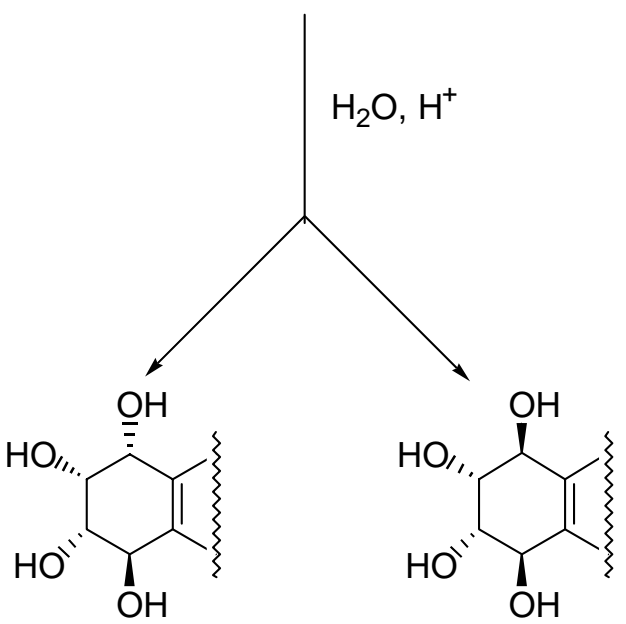

19a (cis)

19b (trans)

Scheme 4. Hydrolysis of 1,2-epoxides of polycyclic substrates.

In principle, the products can be obtained by direct attack at $\mathrm{C}-1$ or $\mathrm{C}-2$ of epoxide ring or by conjugative addition resulting from an attack at C-6. Reactions carried out by using benzeneoxepin-3,6-deuterated indicate that the nucleophilic addition occurs only by 1,2-addition. 
Reaction of 15 with sodium azide and thioethanol resulted in sole attack at C-2 producing trans1-hydroxy-2-azido- and 1-hydroxy-2-ethylthio-1,2-dihydronaphthalenes (Scheme 3).

The acid-catalyzed hydrolysis of the 7,8-dihydroxy-9,10-epoxide metabolite 16 gives cis and trans tetrols $\mathbf{1 8 a}$ and $\mathbf{1 8 b}$ in 92:8 ratio, whereas its stereoisomer $\mathbf{1 7}$, under the same reaction conditions, gives 19a and 19b in 5:95 ratio (Scheme 4). These different ratios of cis- and transtetrols formed from the hydrolysis of $\mathbf{1 6}$ and $\mathbf{1 7}$ was rationalized by a mechanism involving a favorable axial attack of water on the more stable conformation of the benzylic carbocation. ${ }^{21}$ Recently, ${ }^{22}$ the rates of hydrolysis of $\mathbf{1 6}$ and $\mathbf{1 7}$ in water and water-dioxane mixtures have been investigated over a wide range of $\mathrm{pH}$ showing that the reaction yields and the mechanism of nucleophilic attack are $\mathrm{pH}$-dependent.

Table 4. Hydrolysis of aryl 1,2-epoxides catalyzed by APSG/ $\mathrm{I}_{2}$

\begin{tabular}{ccc} 
& & $\mathrm{Ar}$ \\
$\mathrm{Ar}$ & $\mathrm{t}(\mathrm{h})$ & $\mathrm{Yield}(\%)$ \\
$\mathrm{Ph}$ & 1 & 86 \\
$\mathrm{PCl}-\mathrm{C}_{6} \mathrm{H}_{4}$ & 0.75 & 91 \\
$\mathrm{PhOCH}_{2}$ & 5 & 90 \\
\hline
\end{tabular}

Iodine (5-10 mol\%) supported on aminopropyl silica gel (APSG), prepared by reaction of activated silica gel with aminopropyl triethoxy silane, efficiently catalyzed the hydrolysis of aryl 1,2-epoxides ${ }^{23}$ (Table 4).

Table 5. Nucleophlic addition of phenols to (S)-glycidol

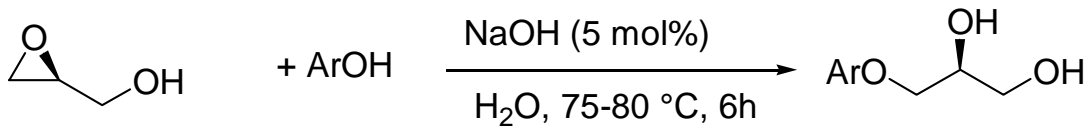

\section{0}

\begin{tabular}{ccc}
\hline $\mathrm{Ar}$ & $\mathrm{t}(\mathrm{h})$ & Yield (\%) \\
\hline$m \mathrm{Pr}^{i}-\mathrm{C}_{6} \mathrm{H}_{4}$ & 14 & 78 \\
$o \mathrm{Pr}^{i}-\mathrm{C}_{6} \mathrm{H}_{4}$ & 12 & 61 \\
$p \mathrm{Cl}-\mathrm{C}_{6} \mathrm{H}_{4}$ & 6 & 86 \\
$p \mathrm{MeO}-\mathrm{C}_{6} \mathrm{H}_{4}$ & 14 & 73 \\
$p \mathrm{Ph}-\mathrm{C}_{6} \mathrm{H}_{4}$ & 14 & 45 \\
$\alpha-\mathrm{Naphthyl}$ & 12 & 62 \\
\hline
\end{tabular}


The nucleophilic additions were carried out in $\mathrm{MeCN} / \mathrm{H}_{2} \mathrm{O}$ mixture at room temperature and the product obtained from cyclohexene oxide showed a total stereospecific anti addition. Enantiopure 3-aryloxy-1,2-propanediols were prepared by nucleophilic ring-opening of (S)glycidol (20) with phenols in water using catalytic amounts of $\mathrm{NaOH}(5 \mathrm{~mol} \%) .{ }^{24}$ The additions were totally regioselective and the optical purity of glycidol was preserved in the products (Table 5). The reactions occurred under heterogeneous conditions and the use of a phase-transfer catalyst did not affect the yield or the reaction times.

\section{Metal Salt Catalyzed Reactions}

Metal salt-promoted nucleophilic ring-opening of 1,2-epoxides were investigated in an attempt to improve the regioselectivity and the reaction rate attained by using classical conditions $\left(\mathrm{NaN}_{3} / \mathrm{NH}_{4} \mathrm{Cl}\right.$, in alcohol or alcohol/water at 70-80 $\left.{ }^{\circ} \mathrm{C}\right)$. Most of the work was carried out in organic solvent using a variety of metal salts $\left(\mathrm{LiClO}_{4}, \mathrm{LiOTf}, \mathrm{Mg}\left(\mathrm{ClO}_{4}\right)_{2}, \mathrm{Zn}(\mathrm{OTf})_{2}, \mathrm{NaClO}_{4}\right.$, $\left.\mathrm{KClO}_{4}, \mathrm{Ti}(\mathrm{O}-\mathrm{i}-\mathrm{Pr})_{4}\right){ }^{12,13,25}$ generally in large excess. Lewis acid-catalyzed reactions carried out in just water have been recently investigated focusing on the azidolysis, ${ }^{5 \mathrm{~d}, 7 \mathrm{a}, 7 \mathrm{~b}, 26 \mathrm{a}}$ iodolysis, ${ }^{7 \mathrm{a}, 26 \mathrm{~b}}$ bromolysis, $^{26 \mathrm{~b}}$ and thiolysis ${ }^{7 \mathrm{c}}$ of 2,3-epoxycarboxylic acids and their esters to develop simple one-pot procedures in aqueous media for the synthesis of hydroxyamino acids, hydroxyacids, and hydroxysulfides.

Table 6. Azidolysis in water of $\alpha, \beta$-epoxycyclohexanecarboxylic acid at $\mathrm{pH} 4.0$ catalyzed by various metal salts

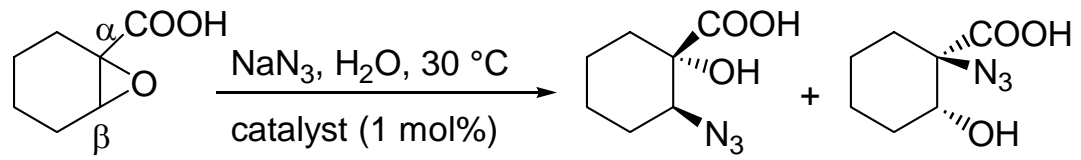

21

$(\mathrm{C}-\beta)$

(C- $\alpha)$

\begin{tabular}{cccc}
\hline Catalyst & $\mathrm{t}(\mathrm{h})$ & $\mathrm{C}^{\mathrm{a}}(\%)$ & $\mathrm{C}-\beta / \mathrm{C}-\alpha$ \\
\hline none & 1.5 & 10 & $>99$ \\
$\mathrm{Yb}(\mathrm{OTf})_{3}$ & 1.5 & 32 & $>99$ \\
$\mathrm{Sc}(\mathrm{OTf})_{3}$ & 1.5 & 30 & $>99$ \\
$\mathrm{InCl}_{3}$ & 1.5 & $>99$ & $>99$ \\
$\mathrm{Cu}\left(\mathrm{NO}_{3}\right)_{2}$ & 1.5 & 93 & $>99$ \\
$\mathrm{AlCl}_{3}$ & 0.3 & $>99$ & $>99$ \\
$\mathrm{Al}_{\left(\mathrm{NO}_{3}\right)_{3}}$ & 0.3 & $>99 \mathrm{~b}$ & $>99$ \\
$\mathrm{AlF}_{3}$ & 1 & 98 & $>99$ \\
\hline
\end{tabular}

a. Reaction conversion; ${ }^{\text {b. }} 4 \%$ of diol was present. 
The azidolysis reaction of $\alpha, \beta$-epoxycyclohexane carboxylic acid (21) (Table 6) was efficaciously catalyzed in water at $\mathrm{pH} 4.0$ and $30^{\circ} \mathrm{C}$ by $1 \mathrm{~mol} \%$ of $\mathrm{Cu}\left(\mathrm{NO}_{3}\right)_{2}, \mathrm{InCl}_{3}, \mathrm{AlCl}_{3}$, $\mathrm{Al}\left(\mathrm{NO}_{3}\right)_{3}$ and $\mathrm{AlF}_{3}$. These salts, with the exception of $\mathrm{Cu}\left(\mathrm{NO}_{3}\right)_{2}$, were not operative at $\mathrm{pH}$ 7.0. $\mathrm{Yb}(\mathrm{OTf})_{3}$, and $\mathrm{Sc}(\mathrm{OTf})_{3}$ were not efficient at either $\mathrm{pH} 4.0$ or at $\mathrm{pH}$ 7.0. The reactions were always highly $\mathrm{C}-\beta$-regioselective.

The catalytic effect of various Lewis acids on the azidolysis of trans- $\alpha, \beta$-epoxyhexanoic acid (22) was also investigated. $\mathrm{Cu}\left(\mathrm{NO}_{3}\right)_{2}, \mathrm{AlCl}_{3}$ and $\mathrm{InCl}_{3}$ were again the best catalysts at $\mathrm{pH}$ 4.0, while $\mathrm{SnCl}_{4}$ showed little activity and $\mathrm{TiCl}_{4}$ slowed the reaction rate; both these salts gave mixtures of C- $\beta$ and $\mathrm{C}-\alpha$ adducts along with large amounts of diols (Table 7).

Table 7. Azidolysis in water of trans- $\alpha, \beta$-epoxyhexanoic acid at $\mathrm{pH} 4.0$ catalyzed by various salts

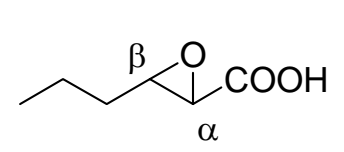

22

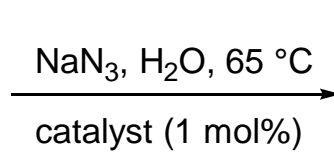

catalyst (1 mol\%)

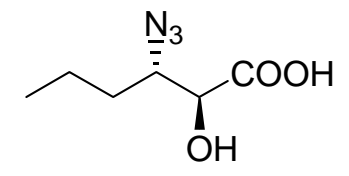

$(\mathrm{C}-\beta)$

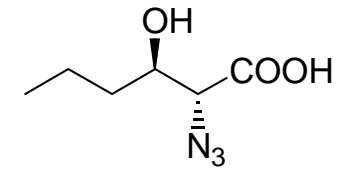

$(\mathrm{C}-\alpha)$

\begin{tabular}{cccc}
\hline Catalyst & $\mathrm{t}(\mathrm{h})$ & $\mathrm{C}^{\mathrm{a}}(\%)$ & $\mathrm{C}-\beta / \mathrm{C}-\alpha$ \\
\hline none & 1.5 & 28 & 1 \\
$\mathrm{Cu}\left(\mathrm{NO}_{3}\right)_{2}$ & 4 & 90 & 16 \\
$\mathrm{AlCl}_{3}$ & 1.5 & $>99$ & $>99$ \\
$\mathrm{InCl}_{3}$ & 2 & $>99$ & $>99$ \\
$\mathrm{TiCl}_{4}$ & 70 & 75 & $1.6^{\mathrm{b}}$ \\
$\mathrm{SnCl}_{4}$ & 8 & 87 & $3^{\mathrm{c}}$ \\
\hline
\end{tabular}

a. Reaction conversion; ${ }^{\text {b. }} 43 \%$ of diol present; ${ }^{\text {c. }} 57 \%$ of diol present.

The stability of $\mathbf{2 2}$ at low $\mathrm{pH}$ values has allowed the investigation of the nucleophilic ring opening of the oxirane ring at $\mathrm{pH} 0-2.0$. The iodolysis and bromolysis reactions were chosen because the very low concentration of azido ions at these $\mathrm{pH}$ values precludes the azidolysis reaction from being carried out under these conditions.

$\mathrm{AlCl}_{3}$ and $\mathrm{InCl}_{3}$ efficaciously catalyzed the iodolysis of 22 at $\mathrm{pH} 1.5$ (Table 8) and the iodoalcohol derived from the anti attack at $\beta$-Carbon was practically the sole reaction product. Under these conditions even $\mathrm{TiCl}_{4}$ and $\mathrm{SnCl}_{4}$ were active catalysts but the process was less regioselective. 
Table 8. Iodolysis in water of trans- $\alpha, \beta$-epoxyhexanoic acid at $\mathrm{pH} 1.5$ catalyzed by various metal salts

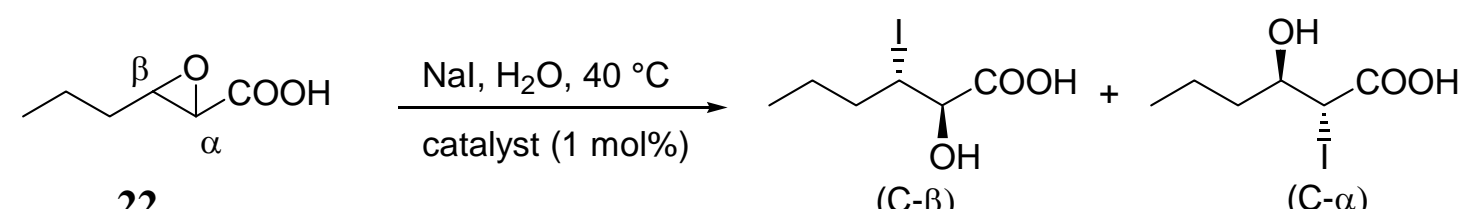

22

(C- $\beta$ )

$(\mathrm{C}-\alpha)$

\begin{tabular}{cccc}
\hline Catalyst & $\mathrm{t}(\mathrm{h})$ & $\mathrm{C}^{\mathrm{a}}(\%)$ & $\mathrm{C}-\beta / \mathrm{C}-\alpha$ \\
\hline none & 0.5 & 18 & 0.6 \\
$\mathrm{AlCl}_{3}$ & 0.5 & 93 & 49 \\
$\mathrm{TiCl}_{4}$ & 2 & 92 & 2 \\
$\mathrm{InCl}_{3}$ & 0.5 & $>99$ & 49 \\
$\mathrm{SnCl}_{4}$ & 0.5 & 92 & 8 \\
\hline
\end{tabular}

a. Reaction conversion.

Table 9. $\mathrm{InCl}_{3}$ effect on the reactivity and selectivity of iodolysis in water of trans- $\alpha, \beta$ epoxyhexanoic acid.

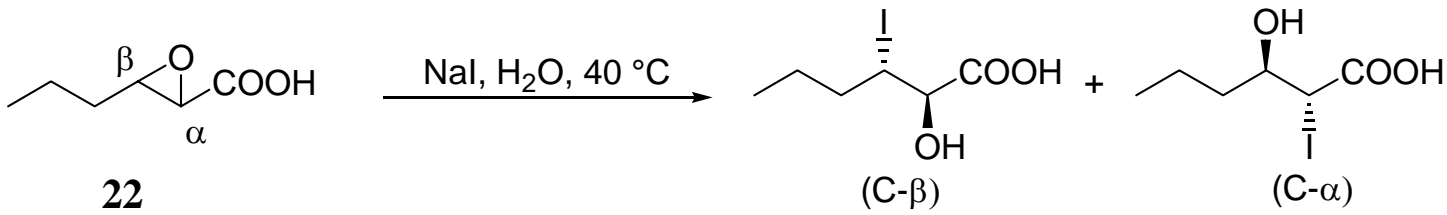

\begin{tabular}{|c|c|c|c|c|c|c|c|c|}
\hline & \multicolumn{4}{|c|}{$\mathbf{W}$} & \multicolumn{4}{|c|}{ With $\mathrm{InCl}_{3}(10 \mathrm{~mol} \%)$} \\
\hline & $\mathrm{pH} 7.0$ & $\mathrm{pH} 4.0$ & $\mathrm{pH} 1.5$ & $\mathrm{pH} 0.0$ & $\mathrm{pH} 7.0$ & $\mathrm{pH} 4.0$ & $\mathrm{pH} 1.5$ & $\mathrm{pH} 0.0$ \\
\hline t (h) & 24 & 64 & 3 & 0.7 & 24 & 2.5 & 0.5 & 0.3 \\
\hline$C^{a}(\%)$ & 2 & 99 & 86 & 98 & 3 & 99 & 100 & 99 \\
\hline $\operatorname{diol}(\%)$ & 0 & 0 & 0 & 0 & 0 & 20 & 0 & 0 \\
\hline C- $\beta(\%)$ & 0 & 1 & 36 & 43 & 0 & 78 & 98 & 65 \\
\hline C- $\alpha(\%)$ & 100 & 99 & 64 & 57 & 100 & 2 & 2 & 35 \\
\hline
\end{tabular}

a. Reaction conversion. 
Table 10. Lewis acid-catalyzed azidolysis in water of $\alpha, \beta$-epoxycarboxylic acids at $\mathrm{pH} 4.0$
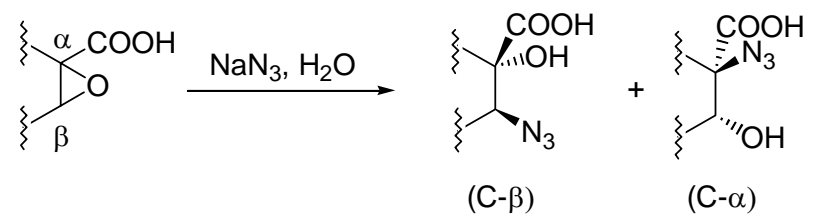

\begin{tabular}{|c|c|c|c|c|c|}
\hline Epoxide & Catalyst (mol\%) & $\mathrm{T}\left({ }^{\circ} \mathrm{C}\right)$ & $t(h)$ & $\mathrm{C}^{\mathrm{a}}(\%)$ & $(C-\beta) /(C-\alpha)$ \\
\hline \multirow{4}{*}{$\mathrm{Me}^{\prime}$} & none & 30 & 16 & 25 & 1 \\
\hline & $\mathrm{Cu}\left(\mathrm{NO}_{3}\right)_{2}(10)$ & 30 & 16 & $>99$ & $>99$ \\
\hline & $\mathrm{AlCl}_{3}(1)$ & 30 & 3.5 & $>99$ & $>99$ \\
\hline & $\mathrm{InCl}_{3}(1)$ & 30 & 10 & $>99$ & $>99$ \\
\hline \multirow{4}{*}{$n-\mathrm{Pr}^{\prime}$} & none & 65 & 24 & 82 & 0.8 \\
\hline & $\mathrm{Cu}\left(\mathrm{NO}_{3}\right)_{2}(10)$ & 30 & 18 & $>99$ & $>99$ \\
\hline & $\mathrm{AlCl}_{3}(1)$ & 65 & 1.5 & $>99$ & $>99$ \\
\hline & $\mathrm{InCl}_{3}(1)$ & 65 & 2 & $>99$ & $>99$ \\
\hline \multirow{4}{*}{$\mathrm{Me}_{\mathrm{Me}}$} & none & 30 & 3 & 13 & $>99$ \\
\hline & $\mathrm{Cu}\left(\mathrm{NO}_{3}\right)_{2}(10)$ & 30 & 3 & $>99$ & $>99$ \\
\hline & $\mathrm{AlCl}_{3}(1)$ & 30 & 0.6 & $>99$ & $>99$ \\
\hline & $\mathrm{InCl}_{3}(1)$ & 30 & 1.2 & $>99$ & $>99$ \\
\hline \multirow{4}{*}{$\mathrm{Me}_{\mathrm{O}_{\mathrm{O}}^{\mathrm{COOH}}}^{\mathrm{COOH}}$} & none & 30 & 8 & 20 & $>99$ \\
\hline & $\mathrm{Cu}\left(\mathrm{NO}_{3}\right)_{2}(10)$ & 30 & 12 & $>99$ & $>99$ \\
\hline & $\mathrm{AlCl}_{3}(1)$ & 30 & 0.75 & $>99$ & $>99$ \\
\hline & $\mathrm{InCl}_{3}(1)$ & 30 & 8 & $>99$ & $>99$ \\
\hline \multirow{3}{*}{$\mathrm{S}_{\mathrm{O}}^{\mathrm{COOH}}$} & none & 30 & 1.5 & 12 & $>99$ \\
\hline & $\mathrm{Cu}\left(\mathrm{NO}_{3}\right)_{2}(10)$ & 30 & 0.25 & $>99$ & $>99$ \\
\hline & $\mathrm{InCl}_{3}(10)$ & 30 & 0.02 & $>99$ & $>99$ \\
\hline \multirow{7}{*}{${ }^{\mathrm{Me}} \chi_{\mathrm{O}}^{\mathrm{COOH}}$} & none & 65 & 20 & $>99$ & $>99$ \\
\hline & $\mathrm{AlCl}_{3}(1)$ & 65 & 0.25 & 99 & 99 \\
\hline & $\mathrm{InCl}_{3}(1)$ & 65 & 2 & $>99$ & $>99$ \\
\hline & none & 30 & 0.25 & 2 & 99 \\
\hline & $\mathrm{Cu}\left(\mathrm{NO}_{3}\right)_{2}(10)$ & 30 & 0.25 & $>99$ & $>99$ \\
\hline & $\mathrm{AlCl}_{3}(1)$ & 30 & 0.25 & 98 & $>99$ \\
\hline & $\mathrm{InCl}_{3}(1)$ & 30 & 1.5 & $>99$ & $>99$ \\
\hline
\end{tabular}

a. Reaction conversion. 
Table 11. $\mathrm{InCl}_{3}$-catalyzed iodolysis in water of $\alpha, \beta$-epoxycarboxylic acids at $\mathrm{pH} 1.5$

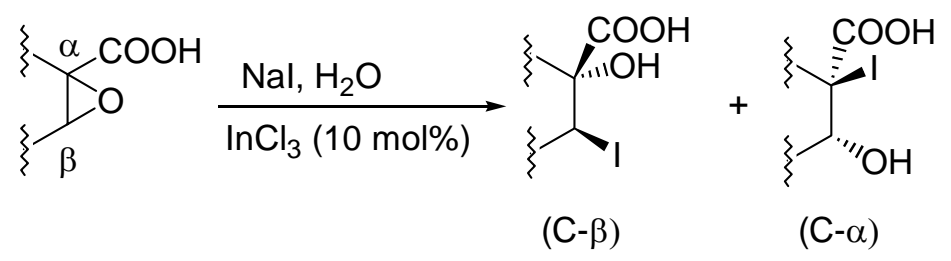

\begin{tabular}{|c|c|c|c|c|c|}
\hline Epoxide & Catalyst & $\mathrm{T}\left({ }^{\circ} \mathrm{C}\right)$ & $\mathrm{t}(\mathrm{h})$ & $C^{a}(\%)$ & $C-\beta / C-\alpha$ \\
\hline $\mathrm{OOH}$ & none & 0 & 2 & 18 & 0.45 \\
\hline & $\mathrm{InCl}_{3}$ & 0 & 2 & 100 & 49 \\
\hline $\mathrm{OOH}$ & none & 40 & 0.5 & 18 & 0.55 \\
\hline & $\mathrm{InCl}_{3}$ & 40 & 0.5 & 100 & 49 \\
\hline & none & 40 & 0.5 & 20 & 99 \\
\hline $\operatorname{Pr}$ & $\mathrm{InCl}_{3}$ & 40 & 0.5 & 100 & 99 \\
\hline & none & 20 & 0.5 & 8 & 1.6 \\
\hline & $\mathrm{InCl}_{3}$ & 20 & 0.5 & 100 & 99 \\
\hline & none & 0 & 0.5 & 12 & 6.7 \\
\hline & $\mathrm{InCl}_{3}$ & 0 & 0.5 & 100 & 99 \\
\hline & none & 0 & 0.5 & 12 & 99 \\
\hline & $\mathrm{InCl}_{3}$ & 0 & 0.5 & 100 & 99 \\
\hline $\mathrm{COOH}$ & none & 0 & 9 & 5 & 99 \\
\hline $2 h^{\prime}$ & $\mathrm{InCl}_{3}$ & 0 & 9 & 100 & 99 \\
\hline
\end{tabular}

a. Reaction conversion.

The study of the $\mathrm{pH}$ dependence of iodolysis of 22 in the presence and in the absence of $\mathrm{InCl}_{3}$ gave some interesting results from a synthetic point of view (Table 9). 
At $\mathrm{pH} 4.0$ the uncatalyzed reaction was complete in $64 \mathrm{~h}$ and only the $\mathrm{C}-\alpha$ adduct was isolated in quantitative yield. At $\mathrm{pH} 1.5$ the $\mathrm{InCl}_{3}$-catalyzed reaction afforded exclusively the $\mathrm{C}-\beta$ regioisomer in $0.5 \mathrm{~h}$.

All these results have been explained by the fact that the catalytic efficiency of Lewis acid salts in water depends on two factors: (i) the $\mathrm{pH}$ of the reaction medium must be below the $\mathrm{pK}_{1,1}$ hydrolysis constant of the aqua ion generated from the dissociation of the salt (presence of aqua ion) and (ii) the ability of the aqua ion to give an active complex with the reagents (affinity of the aqua ion). $\mathrm{Cu}\left(\mathrm{NO}_{3}\right)_{2}, \mathrm{InCl}_{3}$, and $\mathrm{AlCl}_{3}$ generate high concentrations of aqua ions at $\mathrm{pH} \leq 4.0$ and have a great affinity for the $\alpha, \beta$-epoxycarboxylic moiety of 1,2-epoxide and the azide and iodine nucleophiles. A revolutionary insight for the organic chemist is that Lewis acids, such as $\mathrm{AlCl}_{3}$, $\mathrm{TiCl}_{4}$ and $\mathrm{SnCl}_{4}$ believed to be unusable as catalysts in organic reactions carried out in water, are efficacious catalysts in aqueous medium provided that they are used at suitable $\mathrm{pH}$ values.

Table 12. $\mathrm{InBr}_{3}$-catalyzed bromolysis in water of $\alpha, \beta$-epoxycarboxylic acids at $\mathrm{pH} 2.0$

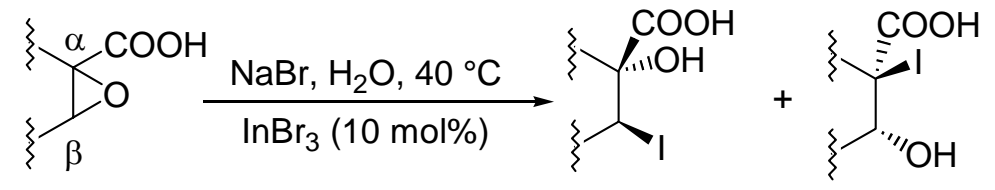

$(\mathrm{C}-\beta) \quad(\mathrm{C}-\alpha)$

\begin{tabular}{ccccc}
\hline Epoxide & Catalyst & $\mathrm{t}(\mathrm{h})$ & $\mathrm{C}^{\mathrm{a}}(\%)$ & $\mathrm{C}-\beta / \mathrm{C}-\alpha$ \\
\hline $\mathrm{K}_{\mathrm{COOH}}^{\mathrm{COH}}$ & none & 0.7 & 18 & 1.5 \\
& $\mathrm{InBr}_{3}$ & 0.7 & 99 & 99
\end{tabular}

$\begin{array}{ccccc}\mathrm{CO}_{\mathrm{n}-\mathrm{Pr}}^{\mathrm{COOH}} & \text { none } & 1.3 & 15 & 1 \\ & \mathrm{InBr}_{3} & 1.3 & 99 & 99\end{array}$

$\begin{array}{lllll}\mathrm{Me} \mathrm{CH}_{\mathrm{Et}}^{\mathrm{COOH}} & \text { none } & 0.5 & 46 & 96 \\ & \mathrm{InBr}_{3} & 0.5 & 99 & 99\end{array}$

\begin{tabular}{rrrrr}
$\mathrm{COOH}$ & none & 0.3 & 47 & 19 \\
$\mathrm{InBr}$ & $\mathrm{InBr}_{3}$ & 0.3 & 99 & 99 \\
\hline
\end{tabular}

a. Reaction conversion. 
These results have lead to the investigation of the azidolysis and iodolysis of a variety of $\alpha, \beta-$ epoxycarboxylic acids in aqueous media catalyzed by Lewis acids (Tables 10 and 11).

The reactions were highly regio- and diastereo-selective and pure anti or trans C- $\beta$-adducts were isolated in high yields. Interestingly, the mother liquors from the work up of the reaction containing the metal ion were reused several times without adding fresh catalyst, and without loss of reaction yield and selectivity.

$\mathrm{InBr}_{3}$ also efficiently catalyzed the bromolysis of $\alpha, \beta$-epoxycarboxylic acids ${ }^{26 \mathrm{~b}}$ (Table 12) producing $\mathrm{C}$ - $\beta$-adducts. However it was difficult to develop a protocol for a wide range of epoxides and sometimes it was difficult to isolate the reaction products so that the reaction yields (32-80\%) were not always satisfactory.The reactivity and regioselectivity of thiolysis of alkyland aryl-1,2-epoxides with thiophenol in water, as the only solvent, was also strongly affected by

Table 13. Phenylthiolysis of the epoxide of methylidenecyclohexane

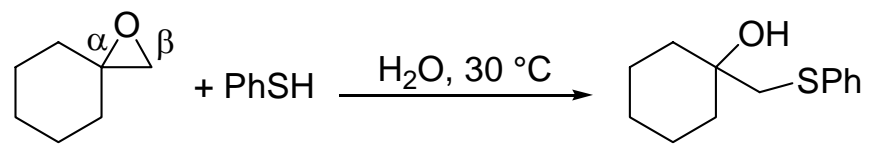

$(\mathrm{C}-\beta)$<smiles>OCC1(S)CCCCC1</smiles>

$(\mathrm{C}-\alpha)$

\begin{tabular}{ccccc}
\hline $\mathrm{pH}$ & $\begin{array}{c}\text { Catalyst }(10 \\
\text { mol\%) }\end{array}$ & $\mathrm{t}(\mathrm{min})$ & $\mathrm{C}-\beta / \mathrm{C}-\alpha$ & Yield (\%) \\
\hline 9.0 & none & 20 & $99 / 1$ & 95 \\
4.0 & none & 1440 & $18 / 82$ & 78 \\
4.0 & $\mathrm{InCl}_{3}$ & 5 & $18 / 82$ & 78 \\
\hline
\end{tabular}

Table 14. Phenylthiolysis of 2-methyl-2,3-epoxyheptane

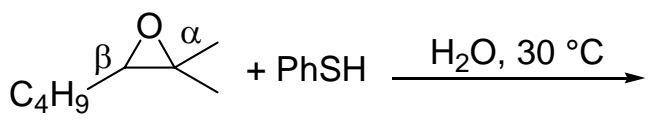<smiles>CCCCCC(C)(C)[SbH2]</smiles>

$(\mathrm{C}-\alpha)$<smiles>CC(C)C(C)(C)O</smiles>

$(\mathrm{C}-\beta)$

\begin{tabular}{ccccc}
\hline $\mathrm{pH}$ & $\begin{array}{c}\text { Catalyst }(10 \\
\text { mol\%) }\end{array}$ & $\mathrm{t}(\mathrm{min})$ & $\mathrm{C}-\beta / \mathrm{C}-\alpha$ & Yield (\%) \\
\hline 9.0 & none & 2880 & $99 / 1$ & 80 \\
4.0 & none & 1440 & $37 / 63$ & 50 \\
4.0 & $\mathrm{InCl}_{3}$ & 10 & $35 / 65$ & 50 \\
\hline
\end{tabular}


the $\mathrm{pH}$ and by the presence of Lewis acids, particularly the $\mathrm{InCl}_{3}{ }^{7 \mathrm{c}}$ The uncatalyzed reaction at $\mathrm{pH} 9.0$ proceeded via the $\mathrm{S}_{\mathrm{N}} 2$ mechanism, and was generally slow (up to $48 \mathrm{~h}$ ) and occurred prevalently $(82-99 \%)$ on the less substituted $\beta$-carbon of unsymmetrical epoxides. When the substituent was a phenyl ring the nucleophile was driven predominantly to the benzylic $\alpha$-carbon by electronic effects. At $\mathrm{pH} 4.0$, in the absence of $\mathrm{InCl}_{3}$, the reaction remained slow or was even slower, but the $\alpha$-regioselectivity strongly increased and in some cases, the $\mathrm{C}$ - $\alpha$ phenylsulfide adduct was the prevalent product. Finally the presence of $10 \% \mathrm{~mol}$ of $\mathrm{InCl}_{3}$ strongly accelerated the reaction that was completed in 3-10 min. Two examples are reported in Table 13 and Table 14.

Coupling the protocol of catalyzed thiolysis of 1,2-epoxides with the preparation of sulfoxides by oxidation of sulfides in water under acidic conditions, ${ }^{27} \beta$-hydroxyphenyl sulfoxides were prepared from epoxides by a one-pot procedure in an aqueous medium. The procedure does not require organic solvent because the sulfoxides precipitate from the aqueous medium and are isolated by simple filtration. These results open the route to the synthesis of building blocks of synthetic interest such as allylic alcohols and ketones by environmentally benign procedures.Chemistry in aqueous media has seriously attracted the attention of organic chemists only during the last ten to fifteen years. Many unexpected results have been obtained already, but many more surprises are to be expected. Perhaps, it is not by chance that nature has chosen water as the reaction medium for its reactions.

\section{Acknowledgments}

The Ministero dell'Istruzione dell'Università e della Ricerca (MIUR) / Università degli Studi di Perugia: Progetto Nazionale ("Eterocicli non aromatici in processi stereocontrollati") and Fondazione Cassa di Risparmio di Perugia are thanked for financial support.

\section{References}

1. (a) Green Chemistry: Challenging Perspectives Eds.;. P. Tundo, P.T. Anastas, Oxford Sc. Pub: 1999. (b) Lester T. Chemistry in Britain 1996, 45.

2. (a) Bröll, D.; Kaul, C.; Krämmer, A.; Richter, A.; Jung, M.; Vogel, H.; Zehner, P. Angew. Chem. Int. Ed. 1999, 38, 2999. (b) Siskin, M.; Katritzky, A.R. Chem. Rev. 2001, 101, 825. (c) Katritzky, A. R.; Nichols, D.A.; Siskin, M.; Murugan, R.; Balasubramanian, M. Chem. Rev. 2001, 101, 837.

3. (a) Weingärtner, H.; Franck, E.U.; Wiegand, G.; Dahmen, N.; Schwedt, G.; Frimmel, F.H.; Gordalla, B.C.; Joannsen, K.; Summers, R.S.; Höll, W.; Jekel, M.; Gimbel, R.; Rautenbach, R.; Glaze, W.H. In Ullmann's Encyclopedia of Industrial Chemistry Vol. A28, Elvers, B.; 
Hawkins, S. Eds. $5^{\text {th }}$ Edn; VCH: Weinheim 1996. (b) Ohtaki, H.; Radnoi, T.; Yamaguchi, T. Chem. Soc. Rev. 1997, 41.

4. Reichardt, C. Solvents and Solvent Effects in Organic Chemistry $2^{\text {nd }}$ Ed; VCH: Weinheim, 1990.

5. (a) Fringuelli, F.; Germani, R.; Pizzo, F.; Santinelli, F.; Savelli, G. J. Org. Chem. 1992, 57, 1198. (b) Ye, D.; Fringuelli, F.;Piermatti, O.; Pizzo, F. J. Org. Chem. 1997, 62, 3748. (c) Fringuelli, F.; Piermatti, O.; Pizzo, F.; Vaccaro, L. J. Org. Chem. 1999, 64, 6094. (d) Fringuelli, F.; Pizzo, F.; Vaccaro, L. Synlett 2000, 311. (e) Brufola, G.; Fringuelli, F.; Piermatti, O.; Pizzo, F. Heterocycles 1996, 43, 1257; 1997, 45, 1715.

6. (a) Li, C.J.; Chang, T.H. Organic Reactions in Aqueous Media, Wiley: N.Y., 1997. (b) Grieco, P. A. Ed.; Organic Synthesis in Water, Blackie Acad. Professional: London, 1998. (c) Fringuelli, F.; Piermatti, O.; Pizzo, F.; Vaccaro, L. Eur. J. Org. Chem. 2001, 439.

7. (a) Fringuelli, F.; Pizzo, F.; Vaccaro, L. J. Org. Chem. 2001, 66, 4719. (b) Fringuelli, F.; Pizzo, F.; Vaccaro, L. Tetrahedron Lett. 2001, 42, 1131. (c) Fringuelli, F.; Pizzo, F.; Tortoioli, S.; Vaccaro, L. Adv. Synth. Catal. 2002, 344, 379.

8. Benson, S.W.; Siebert, E. D. J. Am. Chem. Soc. 1992, 114, 4269.

9. Fringuelli, F.; Piermatti, O.; Pizzo, F. Trends in Organic Chemistry 1997; Vol. 6 Res. Trends Pub. 181.

10. Kolb, H.C.; Finn, M.G.; Sharpless, K.B. Angew. Chem., Int. Ed. 2001, 40, 2005.

11. (a) Coe, D.M.; Myers, P.L.; Parry, D.M.; Roberts, S.M.; Storer, R. J. Chem. Soc., Chem. Comm. 1990, 151; (b) Jacobs, G.A.; Tino, J.A.; Zahler, R. Tetrahedron Lett. 1989, 30, 6955.

12. Chini, M.; Crotti, P.; Macchia, F. Tetrahedron Lett. 1990, 31, 5641.

13. Crotti, P.; Di Bussolo, V.; Favero, L.; Macchia, F.; Pineschi, M. Eur. J. Org. Chem. 1998, 1675.

14. Banwell, M.G.; Haddad, N.; Hudlicky, T.; Nugent, T.C.; Mackay, M.F.; Richards, S.L. J. Chem. Soc., Perkin Trans. 1 1997, 1779.

15. Kavadias, G.; Droghini, R. Can. J. Chem. 1979, 57, 1870.

16. Fringuelli, F.; Germani, R; Pizzo, F.; Savelli, G. Tetrahedron Lett. 1989, 30, 1427.

17. Fringuelli, F.; Pizzo, F; Vaccaro, L. Synthesis 2000, 646.

18. Adams, C.J.; Main, L. Tetrahedron 1991, 47, 4979.

19. Guy, A.; Doussot, J.; Garreau, R.; Godefroy-Falguieres, A. Tetrahedron: Asymmetry 1992, 3, 247.

20. (a) De Marinis, R.M.; Berchtold, G.A. J. Am. Chem. Soc. 1969, 91, 6525. (b) Jeffrey, A.M.; Yeh, H.J.C., Jerina, D.M.; De Marinis, R.M.; Foster, C.H.; Piccolo, D.E.; Berchtold, G.A. J. Am. Chem. Soc. 1974, 96, 6929. (c) Mc Manus, M.J.; Berchtold, G.A. J. Am. Chem. Soc. 1985, 107, 2977.

21. (a) Whalen, D.L.; Montemarano, J.A.; Thakker, D.R.; Yagi, H.; Jerina, D.M. J. Am. Chem. Soc. 1997, 99, 5522.

22. Doan, L.; Lin, B.; Yagi, H.; Jerina, D.M.; Whalen, D.L. J. Am. Chem. Soc. 2001, 123, 6785.

23. Tamami, B.; Iranpoor, N.; Mahdavi, H. Synth. Commun. 2002, 32, 1251. 
24. Palermo, S.; Waykole, L.; Chen, K.-M.; Prashad, M.; Prasad, K.; Repic, O.; Blacklock, T.J. Synth. Commun. 1997, 27, 1757.

25. (a) Chong, J.M.; Sharpless, K.B. J. Org. Chem. 1985, 50, 1560. (b) Thijs, L.; Porskamp, J.J.M.; van Loon, A.A.W.M.; Derks, M.P.W.; Feenstra, R.W.; Legters J.; Zwanenburg, B. Tetrahedron 1990, 46, 2611. (c) Saito, S.; Takahashi, N.; Ishikawa, T.; Morikawa, T. Tetrahedron Lett. 1991, 32, 667. (d) Legters, J.; Thijis, L.; Zwanenburg, B. Recl. Trav. Chim. Pay-Bass 1992, 111, 1. (e) Azzena, F.; Crotti, P.; Favero, L.; Pineschi, M. Tetrahedron 1995, 51, 13409.

26. (a) Fringuelli, F.; Pizzo, F.; Vaccaro, L. J. Org. Chem. 2001, 66, 3554. (b) Amantini, D., Fringuelli, F.; Pizzo, F.; Vaccaro, L. J. Org. Chem. 2001, 66, 4463.

27. Fringuelli, F.; Pellegrino, R.; Pizzo, F. Synth. Commun. 1993, 23, 3157. 